\title{
INFLUENCE OF IRRADIATION SPECTRUM AND \\ IMPLANTED IONS ON THE AMORPHIZATION OF CERAMICS
}

\author{
S.J. Zinkle and L.L. Snead \\ Metals and Ceramics Division, Oak Ridge National Laboratory \\ P.O. Box 2008, Oak Ridge, TN 37831-6376 USA
}

\begin{abstract}
Polycrystalline specimens of alumina $\left(\mathrm{Al}_{2} \mathrm{O}_{3}\right)$, magnesium aluminate spinel $\left(\mathrm{MgAl}_{2} \mathrm{O}_{4}\right)$, magnesia $(\mathrm{MgO})$, silicon nitride $\left(\mathrm{Si}_{3} \mathrm{~N}_{4}\right)$ and silicon carbide $(\mathrm{SiC})$ were irradiated with various ions at temperatures between $200 \mathrm{~K}$ and $450 \mathrm{~K}$, and the microstructures were examined following irradiation using cross-section transmission electron microscopy. Amorphization was not observed in any of the irradiated oxide ceramics, despite damage energy densities up to $\sim 7$ $\mathrm{keV} /$ atom ( 70 displacements per atom). On the other hand, $\mathrm{SiC}$ readily amorphized after damage levels of $\sim 0.4 \mathrm{dpa}$ at room temperature. Silicon nitride exhibited intermediate behavior; irradiation with $\mathrm{Fe}^{++}$ions at room temperature produced amorphization in the implanted ion region after damage levels of -1 dpa. However, irradiated regions outside of the implanted ion region did not amorphize even after damage levels in excess of $5 \mathrm{dpa}$. The amorphous layer in the Fe-implanted region of $\mathrm{Si}_{3} \mathrm{~N}_{4}$ did not appear if the specimen was simultaneously irradiated with $1 \mathrm{MeV} \mathrm{He}{ }^{+}$ions at room temperature. By comparison with published results, it is concluded that the implantation of certain chemical species has a pronounced effect on the amorphization threshold dose of all five materials. Intense ionizing radiation inhibits amorphization in $\mathrm{Si}_{3} \mathrm{~N}_{4}$, but does not appear to significantly influence the amorphization behavior of $\mathrm{SiC}$.
\end{abstract}

Draft manuscript for the proceedings of the 8th International Conference on Radiation Effects in Insulators, Catania, Italy, September 11-15, 1995

Whe submitted manuscript hes been authored by a contractor of the U.S. government under contruct NO. DE-AC05$960 R 22464$. Accordingly, the U.S. Government retains s nonexclusive royalty-free license to publish or reproduce the published form of this contribution, or allow others to do so, for U.S. Govermment purposes:" 


\section{Introduction}

The loss of crystallinity in ceramics due to irradiation with energetic ions has been the topic of numerous studies over the past three decades (see refs. 1-5 for reviews). The displacement dose required to induce amorphization in ceramics at room temperature has been found to vary by more than 3 orders of magnitude, depending on the type of ceramic. Different criteria have been proposed to explain this wide variation in the susceptibility of ceramics to amorphization. These criteria include bond type, free energy of formation, and degree of structural freedom for the polytopes that describe the crystal stacking arrangement [1,4,5]. At the present time, none of these models can completely explain all of the experimental data on amorphization of ceramics. In fact, numerous examples exist where the experimental results on amorphization of a given ceramic do not agree with each other in terms of the amount of displacement damage that is required to produce amorphization [1-5].

It has been recognized for several years that implanted ions can have a significant effect on the dose required to amorphize damage resistant materials. For example, the dose required to amorphize $\mathrm{Al}_{2} \mathrm{O}_{3}$ at room temperature with low-energy $\mathrm{Zr}$ ions is about 50 displacements per atom (dpa), whereas amorphization does not occur during irradiation with ions such as $\mathrm{Nb}$ and $\mathrm{Cr}$ for doses in excess of $100 \mathrm{dpa}$ [3,6,7]. Unfortunately, most of the available results on amorphization of ceramics were obtained using ions with energies $<300 \mathrm{keV}$. Experimental results obtained with ion energies in this range must be treated with caution, due to the complete overlapping of the displacement damage and implanted ion distributions. As discussed elsewhere, the microstructure in the implanted ion region of ceramics has been found to be affected by the implanted ions even for inert or "self-ions" [8].

A further potential complication with the existing experimental data is the uncertain influence of irradiation spectrum (ionizing and displacive) on the amorphization process. The primary knock-on atom (PKA) spectrum is expected to have some influence on the amorphization process, particularly in ceramics that amorphize directly within displacement cascades [5]. In addition, differences in the defect production efficiency for bombarding particles with different PKA energies [9] would affect the amorphization dose, particularly for ceramics that amorphize by point defect accumulation.

There are numerous experimental indications that ionization enhanced diffusion [10-12] may be affecting the microstructural development of ceramics. The high amount of ionization per unit of displacement damage associated with light ion irradiation has been found to inhibit defect cluster nucleation in $\mathrm{MgO}, \mathrm{MgAl}_{2} \mathrm{O}_{4}$ and $\mathrm{Al}_{2} \mathrm{O}_{3}$ [8,13,14], and ionizing radiation has been shown to induce annealing of preexisting point defect swelling in several ceramics at room temperature [15-18]. Several studies on semiconductors have shown that the ionizing radiation 
associated with 50-300 keV electrons promotes the recovery of isolated amorphous regions [1922]. According to the "normal" ionization-enhanced diffusion mechanism [10-12], ionization creates a high concentration of $\mathrm{F}^{+}$centers (oxygen vacancy with 1 trapped electron) which have higher diffusivities than $\mathrm{F}$ centers (oxygen vacancy with 2 trapped electrons). It has been demonstrated by several research groups that ionizing radiation converts $\mathrm{F}$ centers into $\mathrm{F}^{+}$centers in oxide ceramics $[17,23,24]$.

Radiation damage associated with the energetic neutrons produced in proposed fusion reactors presents a considerable challenge for ceramics $[25,26]$. Amorphization cannot be tolerated in ceramics proposed for fusion energy applications due to the accompanying large volume change ( $15 \%$ in $\mathrm{SiC})$ and loss of strength. Therefore, the goal of this study was to use ion beam irradiations to examine the likelihood of amorphization in ceramics being considered for the structure $(\mathrm{SiC})$ and numerous diagnostic and plasma heating systems $\left(\mathrm{MgAl}_{2} \mathrm{O}_{4}, \mathrm{Al}_{2} \mathrm{O}_{3}\right.$, $\mathrm{MgO}, \mathrm{Si}_{3} \mathrm{~N}_{4}$ ) in fusion energy systems $[25,26]$. The materials in this study include ceramics with predominantly covalent bonding ( $\mathrm{SiC}, \mathrm{Si}_{3} \mathrm{~N}_{4}$ ) and predominantly ionic bonding $\left(\mathrm{MgAl}_{2} \mathrm{O}_{4}, \mathrm{Al}_{2} \mathrm{O}_{3}, \mathrm{MgO}\right)$. The samples were irradiated with a variety of ion beams (including some simultaneous dual ion beam irradiations) in order to investigate possible irradiation spectrum effects. The ion energies were $>0.5 \mathrm{MeV}$ in all cases, so that the displacement damage effects could be examined in regions well separated from the implanted ion region. Preliminary descriptions of some of the results contained in this paper have been given elsewhere $[8,27,28]$.

\section{Experimental Procedure}

The specimens for the irradiation studies consisted of single crystal $6 \mathrm{H} \alpha$-SiC (Cree Systems) oriented with the [0001] axis normal to the irradiation surface, and polycrystalline specimens of direct sintered $\mathrm{\beta}-\mathrm{SiC}$ (Cercom), stoichiometric $\mathrm{MgAl}_{2} \mathrm{O}_{4}$ (Ceredyne, Inc.), $\mathrm{Al}_{2} \mathrm{O}_{3}$ (General Electric Lucalox or GTE Wesgo AL995), MgO (Ube Industries UMP) and Si3N4 (Kyocera SN733). The specimens were cut into dimensions of $3 \mathrm{~mm}$ diameter by $0.5 \mathrm{~mm}$ thickness and mechanically polished with $0.3 \mu \mathrm{m}$ diamond paste prior to irradiation. Most of the ion irradiations were performed at room temperature using the triple ion beam Van de Graaff accelerator facility at ORNL [29]. The $0.56 \mathrm{MeV} \mathrm{Si}^{+}$ion irradiations of single crystal $\mathrm{SiC}$ at 300 $\mathrm{K}$ to $450 \mathrm{~K}$ were performed using the NV-500 accelerator at the Surface Modification and Characterization (SMAC) user facility at ORNL. The $4 \mathrm{MeV} \mathrm{Ar}{ }^{+}$ion irradiations of spinel and alumina at $200 \mathrm{~K}$ and $300 \mathrm{~K}$ were performed at Harwell Laboratories. The specimens irradiated in the triple ion beam facility were exposed to several different types of ions, ranging from $0.8 \mathrm{MeV}$ $\mathrm{He}^{+}$to $4 \mathrm{MeV} \mathrm{Zr}^{3+}$ ions. In some cases, the specimens were simultaneously irradiated with dual or triple ion beams. Beam fluxes ranged from 0.2 to $60 \times 10^{16} \mathrm{ions} / \mathrm{m}^{2}-\mathrm{s}$, which produced 
midrange ionizing and displacement per atom (dpa) dose rates of 0.1 to $10 \mathrm{MGy} / \mathrm{s}$ and $10^{-6}$ to $10^{-3}$ $\mathrm{dpa} / \mathrm{s}$, respectively, depending on the ion beam. Further details of the irradiation conditions are given elsewhere $[13,30]$.

The TRIM-90 and -92 computer programs [31] were used to calculate the ionizing and displacement damage doses in $\mathrm{Al}_{2} \mathrm{O}_{3}, \mathrm{SiC}$ and $\mathrm{Si}_{3} \mathrm{~N}_{4}$ for the different ion beams. The measured threshold displacement energies of 24 and $78 \mathrm{eV}$ for the $\mathrm{Al}$ and $\mathrm{O}$ sublattices in $\mathrm{Al}_{2} \mathrm{O}_{3}$ [32] and 22 and $60 \mathrm{eV}$ for the $\mathrm{C}$ and $\mathrm{Si}$ sublattices in SiC [33-35] were used in the TRIM calculations. The $\mathrm{Si}_{3} \mathrm{~N}_{4}$ TRIM calculations used a displacement energy of $40 \mathrm{eV}$ for both sublattices. A sublatticeaveraged threshold displacement energy of $40 \mathrm{eV}$ was used to convert the damage energies obtained from TRIM to the modified Kinchin-Pease dpa value [36], i.e., $1 \mathrm{dpa}=100 \mathrm{eV} / \mathrm{atom}$ damage energy density.

Following irradiation, cross-section transmission electron microscope (TEM) specimens were prepared by gluing the specimens face to face with a similar mechanically polished nonirradiated specimen, sectioning perpendicular to the irradiation surface, mechanical dimpling, and ion milling in a liquid nitrogen cooled stage ( $6 \mathrm{keV} \mathrm{Ar}^{+}$ions, $15^{\circ}$ sputtering angle) until perforation occurred at the glued interface [37]. The specimens were examined by TEM using a Philips CM12 microscope operating at $120 \mathrm{kV}$. Amorphization threshold doses quoted in this paper refer to the dose required to completely amorphize the specimen, as determined by selected area electron diffraction (complete replacement of the crystalline pattern by a diffuse halo pattern) and weak beam dark field electron microscopy.

\section{Results}

Amorphization was not observed in any of the three oxide ceramics $\left(\mathrm{MgAl}_{2} \mathrm{O}_{4}, \mathrm{Al}_{2} \mathrm{O}_{3}\right.$, $\mathrm{MgO}$ ) for the irradiation conditions investigated in this study. Figure 1 shows an example of the general microstructure observed in $\mathrm{MgAl}_{2} \mathrm{O}_{4}$ following irradiation at room temperature with 2$\mathrm{MeV} \mathrm{Al}{ }^{+}$ions to a fluence of $2 \times 10^{21} \mathrm{Al}^{+} / \mathrm{m}^{2}(\sim 50$ dpa peak damage). Amorphization was also not observed in a spinel specimen irradiated at room temperature with $2.4-\mathrm{MeV} \mathrm{Mg}^{+}$ions to a fluence of $3 \times 10^{21} \mathrm{Mg}^{+} / \mathrm{m}^{2}$ ( $\sim 70$ dpa peak damage). Analysis of the irradiated region revealed the presence of interstitial dislocation loops lying on $\{110\}$ and $\{111\}$ habit planes, which were intermixed with network dislocations in the implanted ion/peak damage region. The loops at a depth of $\sim 1 \mu \mathrm{m}$ had an average diameter of $\sim 8 \mathrm{~nm}$ for the specimen shown in Fig. 1, and nearly all of the loops had a Burgers vector of $b=a / 4<110>$. A small fraction of the loops on $\{111\}$ habit planes had $a / 6<111>$ Burgers vectors. An analysis of the dislocation loops observed in spinel irradiated at $200 \mathrm{~K}$ with 4-MeV Ar+ ions to a dose of 5 dpa found that most of the loops were lying on $\{111\}$ habit planes with Burgers vectors of $b=a / 4<110>$. 
Dislocation loops with Burgers vectors of $a / 4<110>$ on $\{111\}$ and $\{110\}$ habit planes represent an intermediate position in the loop evolution process for spinel. It has been shown in previous studies $[38,39]$ that loops in spinel initially form with Burgers vectors of $a / 6<111>$ on $\{111\}$ planes, then unfault on the anion sublattice to form Burgers vectors of $a / 4<110>$. These loops subsequently rotate on their glide cylinder to form perfect loops on $\{110\}$ planes, and eventually interact to form a dislocation network. The Burgers vector and habit plane analysis of the dislocation loops suggests that most of the loops in spinel irradiated at room temperature to doses of 20-70 dpa have unfaulted on the anion sublattice and are in the process of forming dislocation networks. The presence of partially unfaulted loops indicates that the point defects have a significant amount of mobility. This suggests that amorphization would not occur in spinel irradiated at room temperature even at very high doses, since amorphization only occurs when point defect diffusion is very limited. In addition, the presence of dislocation networks in spinel after high dose irradiation provides a very efficient point defect sink, which would further inhibit amorphization.

The microstructure of alumina irradiated at room temperature to doses of 10 to $65 \mathrm{dpa}$ with 2-MeV Al+ ions consisted of a mixture of dislocation loops on the basal and prism planes, along with a dislocation network with a predominant Burgers vector of $a / 3<01 \overline{1} 1>$. Similarly, the microstructure of $\mathrm{MgO}$ irradiated at $300 \mathrm{~K}$ to doses of $\sim 10$ dpa with $2.4 \mathrm{MeV} \mathrm{Mg}^{+}$ions consisted of a mixture of dislocation loops and network dislocations. The presence of network dislocation in these materials is an indicator of significant point defect diffusion, and as mentioned above suggests that amorphization is not possible at higher doses in these ceramics at room temperature in the absence of additional factors such as implanted impurity atoms which might trap the point defects and thereby "lock in" a thermodynamically unstable defect structure. On the other hand, the microstructure of $\mathrm{Al}_{2} \mathrm{O}_{3}$ irradiated at $200 \mathrm{~K}$ with $4-\mathrm{MeV} \mathrm{Ar}+$ ions to a dose of 10 dpa consisted of small defect clusters that were not identifiable as collapsed dislocation loops. This suggests that irradiation of $\mathrm{Al}_{2} \mathrm{O}_{3}$ at lower temperatures or to higher doses at $200 \mathrm{~K}$ might induce amorphization.

Ion irradiation of silicon nitride at room temperature produced a variety of responses, depending on the particular irradiation conditions. As shown in Fig. 2, amorphization occurred in the Fe-implanted region of $\mathrm{Si}_{3} \mathrm{~N}_{4}$ irradiated with $3.6 \mathrm{MeV} \mathrm{Fe}^{++}$ions for fluences as low as $2.2 \times 10^{19} \mathrm{Fe}+/ \mathrm{m}^{2}$ (the lowest $\mathrm{Fe}^{++}$fluence investigated in this study), which corresponds to a peak damage level of $\sim 1.3 \mathrm{dpa}$. The implanted iron concentration in the amorphous region was $\sim 0.1$ at.\%. From the width of the amorphous region and the calculated damage profile, the apparent threshold dose for amorphization can be computed to be $\sim 1.0 \mathrm{dpa}$. In contrast to the low-fluence $\mathrm{Fe}^{++}$ion results, irradiation of $\mathrm{Si}_{3} \mathrm{~N}_{4}$ with $0.8 \mathrm{MeV} \mathrm{He}$ ions at $320 \mathrm{~K}$ to a fluence of $1.5 \times 10^{21} \mathrm{He}^{+} / \mathrm{m}^{2}(\sim 2.6 \mathrm{dpa}$ at the damage peak) did not produce any amorphous region. 
Irradiation of $\mathrm{Si}_{3} \mathrm{~N}_{4}$ with $3.6 \mathrm{MeV} \mathrm{Fe}++$ ions at $300 \mathrm{~K}$ to a fluence of $1.1 \times 10^{20} \mathrm{Fe}^{++/ \mathrm{m}^{2}}(7$ dpa at the damage peak) resulted in an amorphous region centered at the implanted ion depth (Fig. 3) that had a similar width as that observed for the low fluence $\mathrm{Fe}^{++}$ion irradiation. Amorphization was not observed in regions outside of the $\mathrm{Fe}^{++}$ion-implanted region for the high dose $\mathrm{Fe}^{++}$irradiated specimen, despite the presence of displacement damage levels in excess of 5 dpa.

As a final experiment, $\mathrm{Si}_{3} \mathrm{~N}_{4}$ specimens were simultaneously irradiated at room temperature with dual beams of $3.6 \mathrm{MeV} \mathrm{Fe}^{++}$and $1 \mathrm{MeV} \mathrm{He}^{+}$ions in order to investigate possible ionizing radiation effects associated with the $\mathrm{He}$ beam (the range of the $\mathrm{He}$ ions exceeded the $\mathrm{Fe}$ ion range, so the Fe-implanted region was exposed to ionizing radiation from the $\mathrm{He}$ ion beam). The fluence for the Fe ion beam was the same as that used for the high-dose single ion irradiation experiment $\left(1.1 \times 10^{20} \mathrm{Fe}^{++/ \mathrm{m}^{2}}\right)$, and the $\mathrm{He}$ ion fluence was $2.0 \times 10^{21} \mathrm{He}^{+} / \mathrm{m}^{2}$. The total displacement dose in the Fe-implanted region was $\sim 7 \mathrm{dpa}$ (predominantly from the $\mathrm{Fe}$ ion beam), and the associated ionizing radiation dose rate in this region was $\sim 1.6 \mathrm{MGy} / \mathrm{s}(0.35 \mathrm{eV} / \mathrm{atom}-\mathrm{s}$, predominantly from the He ion beam). As shown in Fig. 4, amorphization did not occur in the $\mathrm{Si}_{3} \mathrm{~N}_{4}$ specimens irradiated with these simultaneous dual beams. This suggests that the high ionizing radiation dose rate from the $\mathrm{He}$ ion beam produced annealing of the amorphous regions that ordinarily would have formed in the implanted $\mathrm{Fe}$ region ( $\sim 0.4$ at.\% Fe concentration).

In contrast to the other ceramics studied in this investigation, $\mathrm{SiC}$ was easily amorphized at room temperature for all types of irradiating ions. The amorphization behavior of $\alpha$-SiC and $\beta$ $\mathrm{SiC}$ specimens was found to be very similar. The threshold dose for amorphization near room temperature was determined for $3.6 \mathrm{MeV} \mathrm{Fe}^{++}, 1.8 \mathrm{MeV} \mathrm{Cl}^{+}, 0.56 \mathrm{MeV} \mathrm{Si}^{+}$, and 0.8 and 1.0 $\mathrm{MeV} \mathrm{He}+$ ions. Irradiation of $\alpha-\mathrm{SiC}(6 \mathrm{H}$ polytype) with $3.6 \mathrm{MeV} \mathrm{Fe}++$ ions at $300 \mathrm{~K}$ to a fluence of $1.4 \times 10^{18} \mathrm{Fe}^{++/ m^{2}}$ (0.08 dpa at damage peak) produced small defect clusters throughout the irradiated region, but no amorphization. Irradiation to a fluence of $2.0 \times 10^{19}$ $\mathrm{Fe}^{++} / \mathrm{m}^{2}$ produced complete amorphization in a band $\sim 0.7 \mu \mathrm{m}$ wide centered about the damage peak, suggesting that the threshold dose for complete amorphization was $\sim 0.4$ dpa. Partial amorphization was observed in regions irradiated to doses greater than $\sim 0.2 \mathrm{dpa}$. Irradiation to a fluence of $5.7 \times 10^{19} \mathrm{Fe}^{++} / \mathrm{m}^{2}(0.4 \mathrm{dpa}$ at the surface) amorphized the entire irradiated region, and produced a volumetric expansion of $\sim 15 \%$ [28]. Identical results were also obtained for $\beta$-SiC irradiated with $3.6 \mathrm{MeV} \mathrm{Fe}{ }^{++}$ions [28].

Figure 5 shows the cross-section microstructure of $\alpha$-SiC irradiated at $\sim 320 \mathrm{~K}$ with 0.8 $\mathrm{MeV} \mathrm{He}+$ ions to a fluence of $4.7 \times 10^{21} \mathrm{He}^{+} / \mathrm{m}^{2}(1.3 \mathrm{dpa}$ at the damage peak). Complete amorphization occurred in regions with damage levels greater than $\sim 0.8 \mathrm{dpa}$. The regions adjacent to the amorphous band in SiC contained a high density of small defect clusters (Figs. 57). Dislocation loops on specific habit planes were not resolvable among these defect clusters. 
This suggests that these objects are uncollapsed clusters of point defects, which would induce considerable strain in the lattice compared to dislocation loops. The absence of dislocation loops with resolvable habit planes in $\mathrm{SiC}$ irradiated near room temperature is indicative of low point defect mobility, and is in sharp contrast to the easily resolvable loops that were observed in $\mathrm{MgAl}_{2} \mathrm{O}_{4}, \mathrm{Al}_{2} \mathrm{O}_{3}$ and $\mathrm{MgO}$ (i.e., ceramics that are resistant to room temperature amorphization). Figure 6 shows the enhanced cluster density located on either side of the amorphous band in $\alpha$ $\mathrm{SiC}$ irradiated with $0.8 \mathrm{MeV} \mathrm{He}$ ions.

The effect of ionizing radiation on the amorphization behavior of $\mathrm{SiC}$ irradiated near room temperature was investigated by irradiating several $\beta$-SiC specimens with simultaneous dual beams of $1.8 \mathrm{MeV} \mathrm{Cl}+$ ions and $1 \mathrm{MeV} \mathrm{He}{ }^{+}$ions. The $\mathrm{He}^{+} / \mathrm{Cl}^{+}$particle flux was maintained at $\sim 105$ for the irradiations. Figure 7 shows the microstructure of $\mathrm{SiC}$ irradiated to two different sets of fluence. The range of the $\mathrm{Cl}$ ions was $\sim 0.8 \mu \mathrm{m}$, and the range of the He ions was $\sim 2.4$ $\mu \mathrm{m}$. The calculated peak damage levels for the $\mathrm{He}$ and $\mathrm{Cl}$ beams in the lower fluence irradiation shown in Fig. 7 were 1.1 dpa and 0.3 dpa, respectively. Amorphous bands were observed at the peak damage regions for the $\mathrm{Cl}$ and $\mathrm{He}$ ion beams at both sets of fluence, and the width of the amorphous bands increased with increasing fluence. The threshold dose for complete amorphization was determined to be $\sim 0.6 \mathrm{dpa}$ for the He ion irradiation. The threshold dose in the $\mathrm{Cl}$ ion irradiated region was $\sim 0.1 \mathrm{dpa}$ in the low-fluence specimen (amorphization only in the $\mathrm{Cl}$ ion implanted region), and $\sim 0.4 \mathrm{dpa}$ in the high fluence specimen. This discrepancy in threshold amorphization fluences suggests that the $\mathrm{Cl}$ ions exert a significant chemical effect in the ion-implanted region which results in a lowered threshold for amorphization. The threshold dose for complete amorphization determined in the high-fluence specimen in regions wellseparated from the implanted $\mathrm{Cl}$ ions $(0.4 \mathrm{dpa})$ is in good agreement with the values determined at the surface of specimens irradiated with $3.6 \mathrm{MeV} \mathrm{Fe} e^{++}$ions. This agreement indicates that the ionizing radiation associated with the simultaneous $\mathrm{He}$ ion beam of $\sim 5 \mathrm{MGy} / \mathrm{s}(\sim 1 \mathrm{eV} / \mathrm{atom}-\mathrm{s})$ at a depth of $0.5 \mu \mathrm{m}$ did not have a significant annealing influence on the amorphization process in $\mathrm{SiC}$.

The effect of irradiation temperature on the amorphization threshold dose was investigated in $\alpha$ - and $\beta-S i C$ between 300 and $923 \mathrm{~K}$. Amorphization was not observed in $\mathrm{SiC}$ specimens irradiated with $0.56 \mathrm{MeV} \mathrm{Si}{ }^{+}$ions or $1-\mathrm{MeV} \mathrm{He}^{+}$ions at temperatures above $423 \mathrm{~K}$ for doses up to 21 dpa. Figure 8 summarizes the amorphization threshold data from our studies at temperatures between 300 and $423 \mathrm{~K}$. The damage rates were $\sim 3 \times 10^{-5} \mathrm{dpa} / \mathrm{s}$ for the amorphized midrange regions of the $\mathrm{He}^{+}$ion irradiations, $\sim 1 \times 10^{-4} \mathrm{dpa} / \mathrm{s}$ for the $3.6 \mathrm{MeV} \mathrm{Fe}{ }^{++}$ions, and $\sim 3 \times 10^{-3} \mathrm{dpa} / \mathrm{s}$ for the $0.56 \mathrm{MeV} \mathrm{Si}^{+}$ions. The good agreement between the amorphization threshold dose for the different ions near room temperature suggests that irradiation spectrum and damage rate effects are of minor significance within the range of experimental conditions studied. 
The temperature dependence of the amorphization threshold dose determined from the $0.56 \mathrm{MeV}$ $\mathrm{Si}^{+}$ion irradiations suggests that amorphization is very difficult at temperatures above $400 \mathrm{~K}$.

\section{Discussion}

The absence of amorphization in $\mathrm{MgAl}_{2} \mathrm{O}_{4}, \mathrm{Al}_{2} \mathrm{O}_{3}$ and $\mathrm{MgO}$ in the present study is in general agreement with previous studies on these materials, which have found them to be relatively resistant to amorphization. The main effect of irradiation on $\mathrm{MgAl}_{2} \mathrm{O}_{4}$ has been found to be redistribution of the cations, which creates a disordered spinel structure. Previous studies have found that amorphization did not occur in spinel irradiated at $300 \mathrm{~K}$ for doses of 5 to $80 \mathrm{dpa}$ [27,40-42], which agrees with the present result of no amorphization after a peak dose of $\sim 70$ dpa. As discussed previously [27], the presence of a network dislocation structure in spinel after irradiation to doses of $\sim 50 \mathrm{dpa}$ at room temperature can act as an unsaturable sink for point defects produced during further irradiation. The presence of unfaulted dislocation loops and network dislocations is an indicator of significant point defect mobility, and therefore signifies good resistance to amorphization.

Several recent studies have found that spinel can be amorphized at low temperatures [41,43,44], and also at higher temperatures if certain ions (e.g., $70 \mathrm{MeV} \mathrm{I}$ ) are implanted during the irradiation [45]. Irradiation of spinel with $1.5 \mathrm{MeV} \mathrm{Xe}+$ ions to a dose of $35 \mathrm{dpa}$ at $30 \mathrm{~K}$ produced complete amorphization [44]. Prior to amorphization, electron diffraction analysis showed a weakening of the $<220>$ spinel superlattice spots $[41,43,44]$. This is an indication of significant cation mixing [41,42], and it has been suggested that this may be a necessary precursor to the formation of the amorphous phase [41,43,44]. A slight weakening of the 220 diffraction spots was observed in the spinel specimens irradiated to high doses in the present study. However, the amount of cation mixing after doses as high as $70 \mathrm{dpa}$ was clearly insufficient to trigger the development of an amorphous phase.

The results from previous studies indicate that $\mathrm{Al}_{2} \mathrm{O}_{3}$ can be amorphized at room temperature only if certain implanted ions are present $[3,6,7]$. The threshold amorphization dose at $300 \mathrm{~K}$ ranges from 50 to $>600 \mathrm{dpa}$ for alumina specimens implanted with $100-200 \mathrm{keV} \mathrm{Fe}$, $\mathrm{Cr}, \mathrm{Zr}, \mathrm{Nb}$ and $\mathrm{Mo}$ ions. Implantation of $\mathrm{Zr}$ ions has been found to be particularly effective for inducing amorphization, with loss of crystallinity occurring at fluences where the $\mathrm{Zr} / \mathrm{Al}$ atomic concentration exceeds $6 \%$ [3]. In the present study we did not observe amorphization at room temperature up to a maximum dose of 65 dpa with $\mathrm{Al}$ ions. The presence of large dislocation loops and a network dislocation structure in these specimens suggests that the point defect mobility is sufficiently high to inhibit amorphization at much higher doses (in the absence of point defect trapping by implanted ions), in agreement with the existing data base. 
Amorphization was not observed in the $\mathrm{Al}_{2} \mathrm{O}_{3}$ specimen irradiated to $10 \mathrm{dpa}$ at $200 \mathrm{~K}$ in the present study. However, clearly resolvable dislocation loops or network dislocations were also not observed. This is in sharp contrast to the partially unfaulted dislocation loop structure that was observed in $\mathrm{MgAl}_{2} \mathrm{O}_{4}$ irradiated at the same temperature, and suggests that irradiation of alumina to higher doses at $200 \mathrm{~K}$ or to moderate doses at lower temperatures may induce amorphization. Previous work [3] has found that alumina becomes amorphous after irradiation at $77 \mathrm{~K}$ to a dose of $3 \mathrm{dpa}$. This demonstrates that alumina has somewhat lower resistance to amorphization compared to spinel.

Previous work on ion-irradiated $\mathrm{MgO}$ has found that the threshold amorphization dose varies from $\sim 50 \mathrm{dpa}$ for implantation with $\mathrm{Ti}$ or $\mathrm{Cr}$ ions [7] to greater than $300 \mathrm{dpa}$ for $\mathrm{Nb}$ ion irradiation [46]. The doses achieved in the present study on $\mathrm{MgO}$ (10 dpa) are insufficient to provide further information about the relative stability of $\mathrm{MgO}$ compared to $\mathrm{MgAl}_{2} \mathrm{O}_{4}$ and $\mathrm{Al}_{2} \mathrm{O}_{3}$.

The present results on $\mathrm{Si}_{3} \mathrm{~N}_{4}$ demonstrate that the amorphization behavior of this material is very sensitive to implanted ion and ionizing radiation effects. Amorphization was easily induced in the Fe-implanted regions of $\mathrm{Si}_{3} \mathrm{~N}_{4}$ at room temperature for damage levels of $\sim 1$ dpa (containing $\sim 0.1$ at.\% Fe). However, amorphization did not occur outside of the implanted ion region for doses in excess of $5 \mathrm{dpa}$, and the presence of $\sim 1.6 \mathrm{MGy} / \mathrm{s}(\sim 0.35 \mathrm{eV} /$ atom-s) ionizing radiation inhibited amorphization in Fe implanted regions irradiated up to $\sim 7 \mathrm{dpa}$ (containing 0.4 at.\% Fe). The relatively high resistance of silicon nitride to amorphization outside of the $\mathrm{Fe}$ implanted region agrees with a previous study which found that $\mathrm{Si}_{3} \mathrm{~N}_{4}$ did not amorphize during $\mathrm{Kr}$ ion irradiation at $300 \mathrm{~K}$ for damage levels in excess of $100 \mathrm{dpa}$ [47].

Numerous previous studies on $\mathrm{SiC}$ have found that the threshold dose for complete amorphization near $300 \mathrm{~K}$ is 0.2 to $0.6 \mathrm{dpa}$ [28,48-52]. The presence of uncollapsed clusters of point defects in SiC observed in the present study is indicative of low point defect mobility, which would promote the formation of the amorphous phase. The threshold dose for complete amorphization at $300 \mathrm{~K}$ obtained in the present study was 0.4 to $0.6 \mathrm{dpa}$, in good agreement with previous work, and the threshold dose rises rapidly with increasing irradiation temperature above $300 \mathrm{~K}$ (Fig. 8).

Figure 9 compares the present data with previously published results on the temperaturedependent amorphization threshold dose in $\mathrm{SiC}$ [52-54]. The damage levels from the previous studies have been recalculated in order to maintain consistency with the present results. In particular, the damage energies for the 2-MeV electrons were recalculated using Oen's tables [55] assuming threshold displacement energies of 22 and $60 \mathrm{eV}$ for the $\mathrm{C}$ and $\mathrm{Si}$ sublattices [33-35]. In addition, the incident surface damage level was used for the Xe ion data rather than the higher quoted midrange damage level [52], since the lower-dose incident surface region would be the last to amorphize and the criterion of complete amorphization was used in Fig. 9. A sublattice- 
averaged displacement energy of $40 \mathrm{eV}$ was used to convert all of the damage energies to dpa values. The damage rate was $\sim 2 \times 10^{-3} \mathrm{dpa} / \mathrm{s}$ in all of the studies. Whereas our data (Fig. 8 ) did not indicate any significant dependence of the amorphization threshold dose on irradiation spectrum for $\mathrm{He}, \mathrm{Si}, \mathrm{Cl}$ or $\mathrm{Fe}$ ions at room temperature, the data in Fig. 9 suggests that significant differences occur for very low energy PKA (electrons) and high energy PKA (Xe ions) irradiations.

The two different curves for the electron irradiation studies [53,54] inFig. 9 represent the reported behavior for $\alpha-\mathrm{SiC}$ (oriented with the c-axis normal to the irradiation surface) and $\beta$ $\mathrm{SiC}$, with critical crystalline-to-amorphous transition temperatures of $\sim 290 \mathrm{~K}$ and $\sim 340 \mathrm{~K}$, respectively. The reported behavior for $\alpha$-SiC oriented with the a-axis normal to the irradiation surface was similar to the $\beta-\mathrm{SiC}$ at low temperatures, but at higher temperatures this orientation exhibited a critical crystalline-amorphous transition temperature that was the same as the c-axis orientation, i.e., $290 \mathrm{~K}$ [53]. These data imply that there may be some difference in the amorphization behavior of $\alpha$ - and $\beta$-SiC, particularly for $\alpha$-SiC with the c-axis orientation. However, it should be pointed out that another electron irradiation study found identical amorphization behavior for $\beta-\mathrm{SiC}$ and $\alpha-\mathrm{SiC}$ with the $\mathrm{c}$-axis orientation, with a low-temperature threshold amorphization dose of $\sim 0.66 \mathrm{dpa}$ and a critical crystalline-amorphous transition temperature of $\sim 300 \mathrm{~K}$ [56]. No significant difference between the amorphization behavior of $\alpha$ and $\beta-\mathrm{SiC}$ was observed in the present study for irradiation with $\mathrm{He}$ or $\mathrm{Fe}$ ions.

The results of the present and previously published experiments indicate that $\mathrm{MgAl}_{2} \mathrm{O}_{4}$ and $\mathrm{MgO}$ have the highest resistance to amorphization of the five materials, followed in order by $\mathrm{Al}_{2} \mathrm{O}_{3}, \mathrm{Si}_{3} \mathrm{~N}_{4}$, and $\mathrm{SiC}$. This experimentally determined ranking is in good agreement with predictions for amorphization resistance made according to bonding type (ionicity) [1,2,4] and available structural freedom [5] models. Additional experimental studies conducted on materials with a wide range of ionicities within a given crystal structure are needed to further assess the applicability of these two models [4]. These data should be obtained under experimental conditions that minimize or eliminate the influence of implanted ions in order to better evaluate the intrinsic amorphization behavior in different types of ceramics. The present results and previous studies clearly show that implanted ions can have a significant effect on the amorphization threshold dose for ceramics, particularly for "damage-resistant" ceramics such as $\mathrm{MgAl}_{2} \mathrm{O}_{4}, \mathrm{Al}_{2} \mathrm{O}_{3}$ and $\mathrm{MgO}$. An evaluation of the existing data suggests that these three materials cannot be amorphized at room temperature without the aid of implanted ions.

\section{Conclusions}


The amorphization tendencies of the five materials examined can be summarized as follows: Amorphization does not occur during room temperature irradiation of $\mathrm{MgAl}_{2} \mathrm{O}_{4}, \mathrm{Al}_{2} \mathrm{O}_{3}$ or $\mathrm{MgO}$ in the absence of implanted ion chemical effects, at least for doses up to $100 \mathrm{dpa}$ ( $10 \mathrm{keV} / \mathrm{atom}$ damage energy). Amorphization can be induced at room temperature by the implantation of certain ion species, e.g. I in spinel, $\mathrm{Zr}$ in alumina, and $\mathrm{Ti}$ in magnesia. Silicon nitride cannot be amorphized during room temperature irradiation up to doses of at least $7 \mathrm{dpa}$ (and probably 100 dpa) unless certain implanted ions are present. The presence of $\mathrm{Fe}$ ions reduces the amorphization threshold dose of $\mathrm{Si}_{3} \mathrm{~N} 4$ to $<1 \mathrm{dpa}(\leq 0.1$ at.\% $\mathrm{Fe})$. SiC completely amorphizes at room temperature for doses greater than about $0.4 \mathrm{dpa}$. The amorphization threshold dose is only about $0.1 \mathrm{dpa}$ in $\mathrm{Cl}$-implanted regions of $\mathrm{SiC}$.

The effect of the PKA and ionizing radiation spectrum is uncertain in the three oxide ceramics, due to their high resistance to amorphization at room temperature. On the other hand, an ionizing radiation dose rate of $\sim 1.6 \mathrm{MGy} / \mathrm{s}(\sim 0.35 \mathrm{eV} /$ atom-s $)$ clearly inhibits amorphization in Fe-implanted regions of silicon nitride, which suggests that ionization enhanced diffusion may be counteracting the implanted ion effect. There was no apparent effect of PKA spectrum on the amorphization threshold dose in $\mathrm{SiC}$ irradiated near room temperature with $\mathrm{He}, \mathrm{Cl}, \mathrm{Si}$ and $\mathrm{Fe}$ ions. However, published data obtained with electrons and $\mathrm{Xe}$ ions suggest that the lowtemperature amorphization dose increases by about a factor of 5 as the irradiation source is changed from electrons to $\mathrm{Xe}$ ions. Ionizing radiation dose rates up to $5 \mathrm{MGy} / \mathrm{s}(\sim 1 \mathrm{eV} /$ atom-s $)$ did not affect the room temperature amorphization threshold dose in $\mathrm{SiC}$ irradiated with $\mathrm{Cl}$ ions.

In the absence of implanted ion effects, the ranking of these five materials with regard to increasing resistance to amorphization is $\mathrm{SiC}, \mathrm{Si}_{3} \mathrm{~N}_{4}, \mathrm{Al}_{2} \mathrm{O}_{3}$, and $\mathrm{MgAl}_{2} \mathrm{O}_{4}$ and $\mathrm{MgO}$. There is insufficient data to determine whether spinel or $\mathrm{MgO}$ has the highest resistance to amorphization, although it is clear that both of these materials (along with alumina) are very resistant to amorphization.

\section{Acknowledgements}

The authors thank Sy Cook, Steven Withrow and D.K. Thomas for performing most of the ion irradiations, and Wade Jones and Alex Fisher for preparation of the cross-section TEM specimens. This research was sponsored by the Office of Fusion Energy, U.S. Department of Energy, under contract DE-AC05-96OR22464 with Lockheed Martin Energy Systems, Inc. 


\section{References}

[1] H.M. Naguib and R. Kelly, Radiat. Effects 25 (1975) 1.

[2] Hj. Matzke, Radiat. Effects 64 (1982) 3.

[3] C.W. White, C.J. McHargue, P.S. Sklad, L.A. Boatner and G.C. Farlow, Mater Sci. Rep. 4 (1989) 41.

[4] R.C. Ewing, L.M. Wang and W.J. Weber, in Microstructure of Irradiated Materials, edited by I.M. Robertson et al. (Mater. Res. Soc., Pittsburgh, PA, 1995) p. 347.

[5] L.W. Hobbs, J.Non-Crystalline Solids 182 (1995) 27.

[6] C.J. McHargue et al., Nucl. Instr. Meth. B 16 (1986) 212.

[7] P.J. Burnett and T.F. Page, Radiation Eff. 97 (1986) 283.

[8] S.J. Zinkle, Nucl. Instr. Meth. Phys. Res. B 91 (1994) 234.

[9] P. Agnew, Nucl. Instr. Meth. Phys. Res. B 65 (1992) 305.

[10] J.W. Corbett and J.C. Bourgoin, IEEE Trans. Nucl. Sci. NS-18 , No. 6 (1971) 11.

[11] J.C. Bourgoin, J.W. Corbett and H.L. Frisch, J. Chem. Phys. 59 (1973) 4042.

[12] J.W. Corbett and J.C. Bourgoin, Radiat. Effects 36 (1978) 157.

[13] S.J. Zinkle, J. Nucl. Mater. 219 (1995) 113.

[14] S.J. Zinkle, in Microstructure of Irradiated Materials, MRS Symp. Proc. Vol. 373, eds. I.M. Robertson et al. (Mater. Res. Soc., Pittsburgh, 1995) p.

[15] D.G. Walker, J. Nucl. Mater. 14 (1964) 195.

[16] G.W. Arnold, G.B. Krefft and C.B. Norris, Appl. Phys. Lett. 25 (1974) 540.

[17] G.B. Krefft, J. Vac. Sci. Technol. 14 (1977) 533.

[18] G.B. Krefft and E.P. EerNisse, J. Appl. Phys. 49 (1978) 2725.

[19] M.O. Ruault, J. Chaumont, J.M. Penisson and A. Bourret, Phil. Mag. A 50 (1984) 667.

[20] H. Abe, C. Kinoshita, Y. Denda and T. Sonoda, Proc. Jap. Acad., Ser. B, 69, No. 7 (1993) 173.

[21] H. Abe, C. Kinoshita, P.R. Okamoto and L.E. Rehn, J. Nucl. Mater. 212-215 (1994) 298.

[22] I. Jencic, M.W. Bench, I.M. Robertson and M.A. Kirk, in Microstructure of Irradiated Materials, MRS Symp. Proc. Vol. 373, eds. I.M. Robertson et al. (Mater. Res. Soc., Pittsburgh, 1995) p. 481.

[23] M.L. Dalal, M. Rahmani and P.D. Townsend, Nucl. Instr. Meth. Phys. Res. B 32 (1988) 61.

[24] R. Brenier, B. Canut, L. Gea, S.M.M. Ramos, P. Thevenard, J. Rankin, L. Romana and L.A. Boatner, Nucl. Instr. Meth. Phys. Res. B 80/81 (1993) 1210.

[25] S.J. Zinkle and E.R. Hodgson, J. Nucl. Mater. 191-194 (1992) 58.

[26] J.L. Scott, F.W. Clinard, Jr. and F.W. Wiffen, J. Nucl. Mater. 134\&135 (1995) 156.

[27] S.J. Zinkle and S. Kojima, Nucl. Instr. Meth. Phys. Res. B 46 (1990) 165. 
[28] L.L. Snead and S.J. Zinkle, in Microstructure of Irradiated Materials, MRS Symp. Proc. Vol. 373, eds. I.M. Robertson et al. (Mater. Res. Soc., Pittsburgh, 1995) p. 377.

[29] M.B. Lewis, W.R. Allen, R.A. Buhl, N.H. Packan, S.W. Cook, and L.K. Mansur, Nucl. Instr. Meth. Phys. Res. B 43 (1989) 243.

[30] S.J. Zinkle, in 15th Int. Symp. on Effects of Radiation on Materials, ASTM STP 1125, R.E. Stoller, et al., eds. (Amer. Soc. for Testing and Materials, Philadelphia, 1992) 749.

[31] J.F. Ziegler, J.P. Biersak and U.L. Littmark, The Stopping and Range of Ions in Solids (Pergamon Press, New York, 1985). The calculations in the present paper used the TRIM-90 and -92 versions.

[32] P. Agnew, Philos. Mag. A 65 (1992) 355.

[33] I.I. Geitsi, A.A. Nesterova and L.S. Smirnov, Sov. Phys. Semicond. 5 (1971) 439.

[34] B. Hudson and B.E. Sheldon, J. Microsc. 97 (1973) 113.

[35] A.L. Barry, B. Lehmann, D. Fritsch and D. Braunig, IEEE Trans. Nucl. Sci. 38 (1991) 1111.

[36] M.J. Norgett, M.T. Robinson and I.M. Torrens, Nucl. Eng. Design 33 (1975) 50.

[37] S.J. Zinkle, C.P. Haltom, L.C. Jenkins, and C.K.H. DuBose, J. Electron Microsc. Techn. 19 (1991) 452.

[38] C. Kinoshita, J. Nucl. Mater. 191-194 (1992) 67.

[39] K. Fukumoto, C. Kinoshita, S. Maeda and K. Nakai, Nucl. Instr. Meth. Phys. Res. B 91 (1994) 252.

[40] N. Iwamoto, S. Endo and Y. Makino, Radiat. Eff. 97 (1986) 243.

[41] N. Yu, K.E. Sickafus and M. Nastasi, in Microstructure of Irradiated Materials, MRS Symp. Proc. Vol. 373, eds. I.M. Robertson et al. (Mater. Res. Soc., Pittsburgh, 1995) p. 401.

[42] L.M. Wang, W.L. Gong, N. Bordes, R.C. Ewing and Y. Fei, in Microstructure of Irradiated Materials, MRS Symp. Proc. Vol. 373, eds. I.M. Robertson et al. (Mater. Res. Soc., Pittsburgh, 1995) p. 407.

[43] N. Yu, K.E. Sickafus and M. Nastasi, Philos. Mag. Lett. 70 (1994) 235.

[44] K.E. Sickafus, 8th Int. Conf. on Radiation Effects in Insulators, Catania, Italy, to be published in Nucl. Instr. Meth. B (these proceedings).

[45] Hj. Matzke, 8th Int. Conf. on Radiation Effects in Insulators, Catania, Italy, to be published in Nucl. Instr. Meth. B (these proceedings).

[46] S.M.M. RamosB. Canut, L. Gea, L. Romana, J. LeBrusq, P. Thevenard and M. Brunel, Nucl. Instr. Meth. B 59/60 (1991) 1201.

[47] L. Cartz, F.G. Karioris and R.A. Fournelle, Radiat. Eff. 54 (1981) 57.

[48] C.J. McHargue and J.M. Williams, Nucl. Instr. Meth. B 80/81 (1993) 889. 
[49] J.A. Spitznagel, S. Wood, W.J. Choyke, N.J. Doyle, J. Bradshaw and S.G. Fishman, Nucl. Inst. Meth. B16 (1986) 237.

[50] J.A. Edmond, R.F. Davis, S.P. Withrow and K.L. More, J. Mater. Res. 3 (1988) 321.

[51] N.G. Chechenin, K.K. Bourdelle, A.V. Suvorov, and A.X. Kastilio-Vitloch, Nucl Instr. Meth. B65 (1992) 341.

[52] W.J. Weber and L.M. Wang, in Proc. 9th Int. Conf. Ion Beam Modification of Materials, Nucl. Instr. Meth. B, in press (1995)

[53] H. Inui, H. Mori and H. Fujita, Philos. Mag. B 61 (1990) 107.

[54] H. Inui, H. Mori, A. Suzuki and H. Fujita, Philos. Mag. B 65 (1992) 1.

[55] O.S. Oen, Cross Sections for Atomic Displacement in Solids by Fast Electrons, ORNL-4897 (1973).

[56] A. Matsunaga, C. Kinoshita, K. Nakai, and Y. Tomokiyo, J. Nucl. Mater. 179-181 (1991) 457.

\section{DISCLAIMER}

This report was prepared as an account of work sponsored by an agency of the United States Government. Neither the United States Government nor any agency thereof, nor any of their employees, makes any warranty, express or implied, or assumes any legal liability or responsibility for the accuracy, completeness, or usefulness of any information, apparatus, product, or process disclosed, or represents that its use would not infringe privately owned rights. Reference herein to any specific commercial product, process, or service by trade name, trademark, manufacturer, or otherwise does not necessarily constitute or imply its endorsement, recommendation, or favoring by the United States Government or any agency thereof. The views and opinions of authors expressed herein do not necessarily state or reflect those of the United States Government or any agency thereof. 


\section{List of Figures}

Fig. 1. General cross-section microstructure of $\mathrm{MgAl}_{2} \mathrm{O}_{4}$ irradiated at $300 \mathrm{~K}$ with $2-\mathrm{MeV} \mathrm{Al}^{+}$ions to a fluence of $2 \times 10^{21} \mathrm{Al}^{+} / \mathrm{m}^{2}$.

Fig. 2. Amorphous layer near the implanted ion region in $\mathrm{Si}_{3} \mathrm{~N}_{4}$ irradiated at $300 \mathrm{~K}$ with $3.6-\mathrm{MeV}$ $\mathrm{Fe}^{++}$ions to a fluence of $2.2 \times 10^{19} \mathrm{Fe}^{++} / \mathrm{m}^{2}$. The residual contrast visible in the amorphous region is due to $\mathrm{Y}_{2} \mathrm{O}_{3}$-enriched grain boundaries in the silicon nitride.

Fig. 3. Amorphous layer associated with the implanted ion region in $\mathrm{Si}_{3} \mathrm{~N}_{4}$ irradiated at $300 \mathrm{~K}$ with $3.6-\mathrm{MeV} \mathrm{Fe}{ }^{++}$ions to a fluence of $1.1 \times 10^{20} \mathrm{Fe}^{++} / \mathrm{m}^{2}$. Note the absence of amorphization at a depth $\sim 1.5 \mu \mathrm{m}$, where the damage exceeds $5 \mathrm{dpa}$.

Fig. 4. General cross-section microstructure of $\mathrm{Si}_{3} \mathrm{~N}_{4}$ simultaneously irradiated at $300 \mathrm{~K}$ with 3.6$\mathrm{MeV} \mathrm{Fe} e^{++}$ions $\left(1.1 \times 10^{20} \mathrm{Fe}^{++/ \mathrm{m}^{2}}\right)$ and $1-\mathrm{MeV} \mathrm{He}^{+}$ions $\left(2.0 \times 10^{21} \mathrm{He}^{+/ \mathrm{m}^{2}}\right)$. The He ion beam suppresses amorphization, presumably due to ionization-enhanced annealing effects (see text).

Fig. 5. Cross-section microstructure of $\alpha-\mathrm{SiC}$ irradiated at $\sim 320 \mathrm{~K}$ with $0.8 \mathrm{MeV} \mathrm{He}{ }^{+}$ions to a fluence of $4.7 \times 10^{21} \mathrm{He}^{+} / \mathrm{m}^{2}$. The damage rate at a depth of $1.5 \mu \mathrm{m}$ was $\sim 3 \times 10^{-5} \mathrm{dpa} / \mathrm{s}$.

Fig. 6. Weak beam microstructure of the amorphous and crystalline regions of $\alpha-S i C$ irradiated at $\sim 320 \mathrm{~K}$ with $0.8 \mathrm{MeV} \mathrm{He}^{+}$ions to a fluence of $4.7 \times 10^{21} \mathrm{He}^{+} / \mathrm{m}^{2}$. The specimen is completely amorphous at depths between 1.6 and $2.13 \mu \mathrm{m}$.

Fig. 7. Cross-section microstructure of $\beta-\mathrm{SiC}$ simultaneously irradiated at $\sim 320 \mathrm{~K}$ with $1.8 \mathrm{MeV}$ $\mathrm{Cl}^{+}$ions and $1 \mathrm{MeV} \mathrm{He}+$ ions to two different sets of fluence. The $\mathrm{He}^{+} / \mathrm{Cl}^{+}$particle ratio was 105 in both cases.

Fig. 8. Summary of measurements on temperature-dependent amorphization threshold dose in SiC. The unfilled circle at $423 \mathrm{~K}, 21$ dpa denotes a specimen that did not amorphize.

Fig. 9. Comparison of measurements on the temperature-dependent amorphization threshold dose in SiC [52-54]. The unfilled data points denote specimens that did not completely amorphize. 


\section{MICROSTRUCTURE OF $\mathrm{MgAl}_{2} \mathrm{O}_{4}$ IRRADIATED WITH 2-MeV Al+ IONS AT $300 \mathrm{~K}$ TO $1 \times 10^{20} \mathrm{Al}+\mathrm{m}^{2}$}

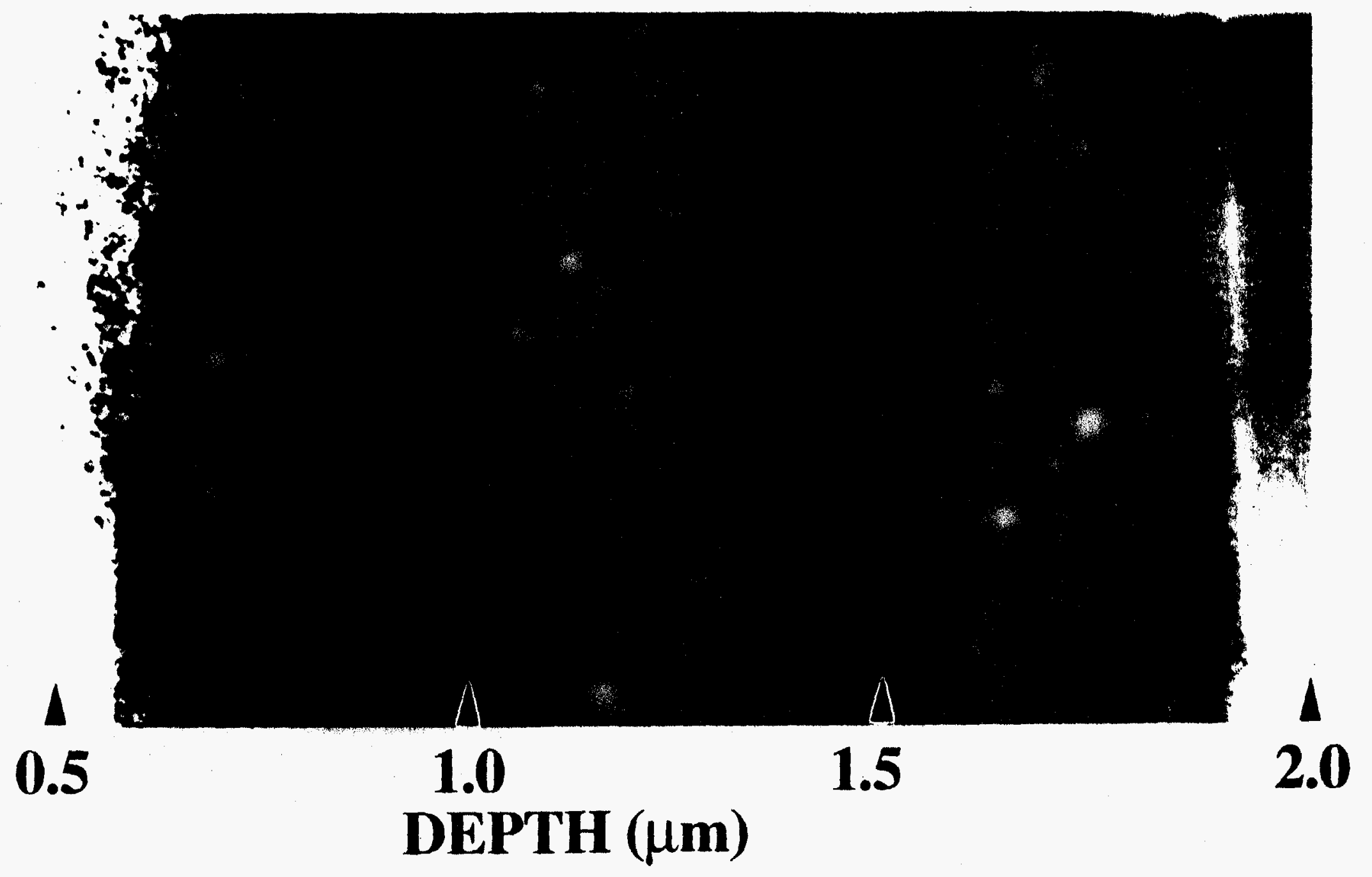




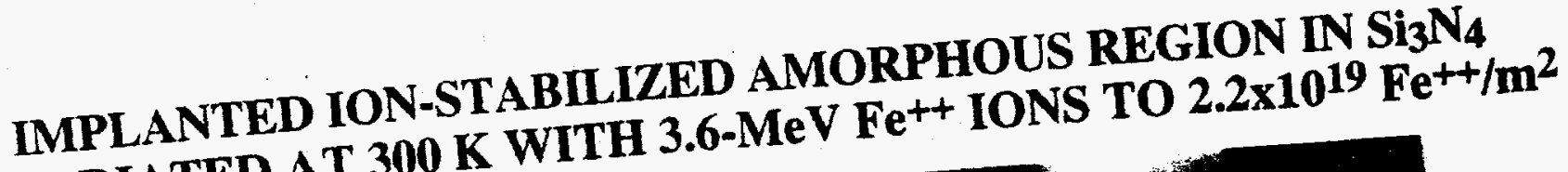
IRRADIATED AT $300 \mathrm{~K}$ WITH 3.6-MeV Fe

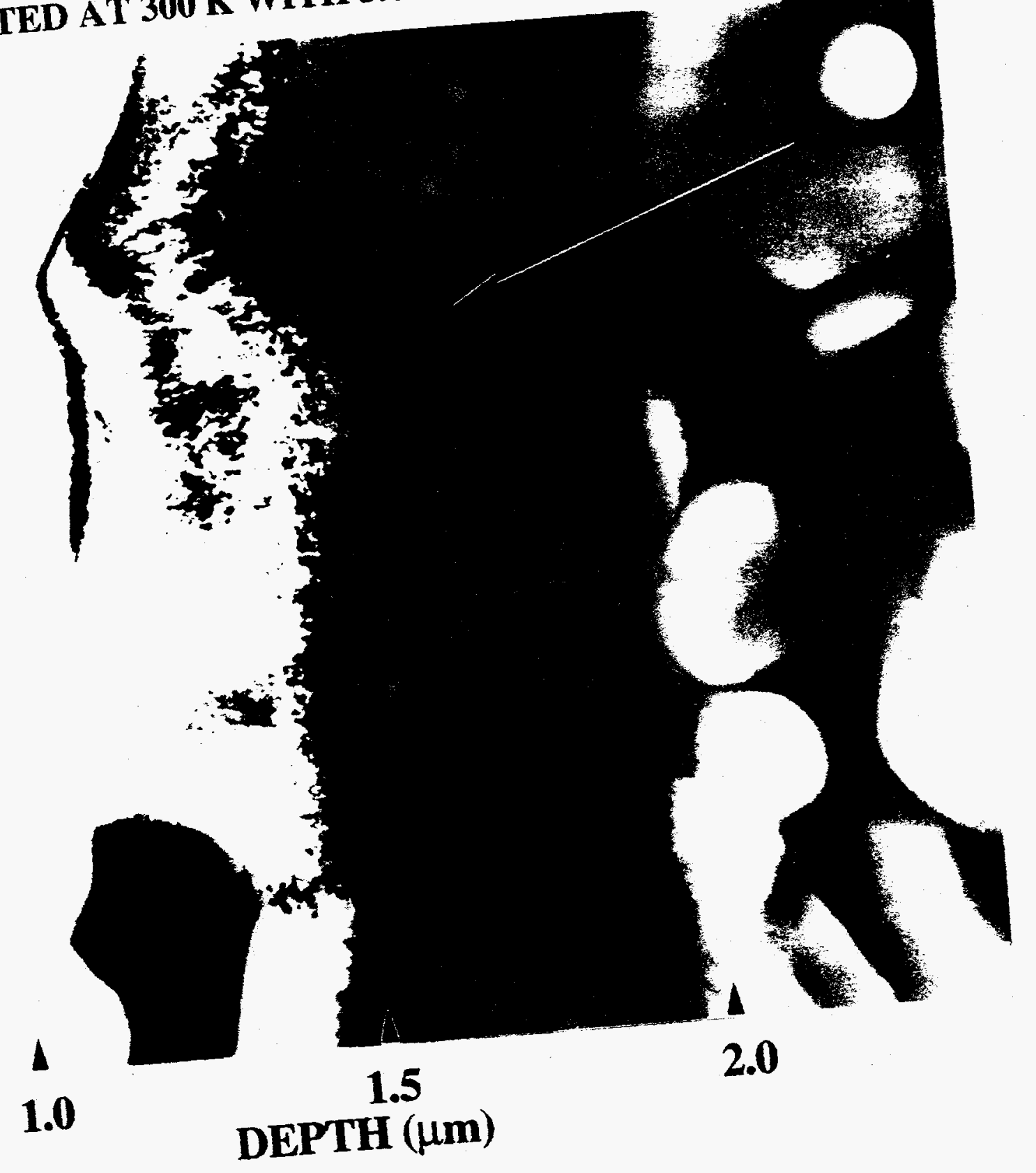


ORNL-PHOTO $1280-95$

\section{AMORPHOUS REGION IN Si3N4 IRRADIATED} AT $300 \mathrm{~K}$ WITH 3.6-MeV Fe++ IONS TO $1.1 \times 10^{20} \mathrm{Fe}^{++/ \mathrm{m}^{2}}$

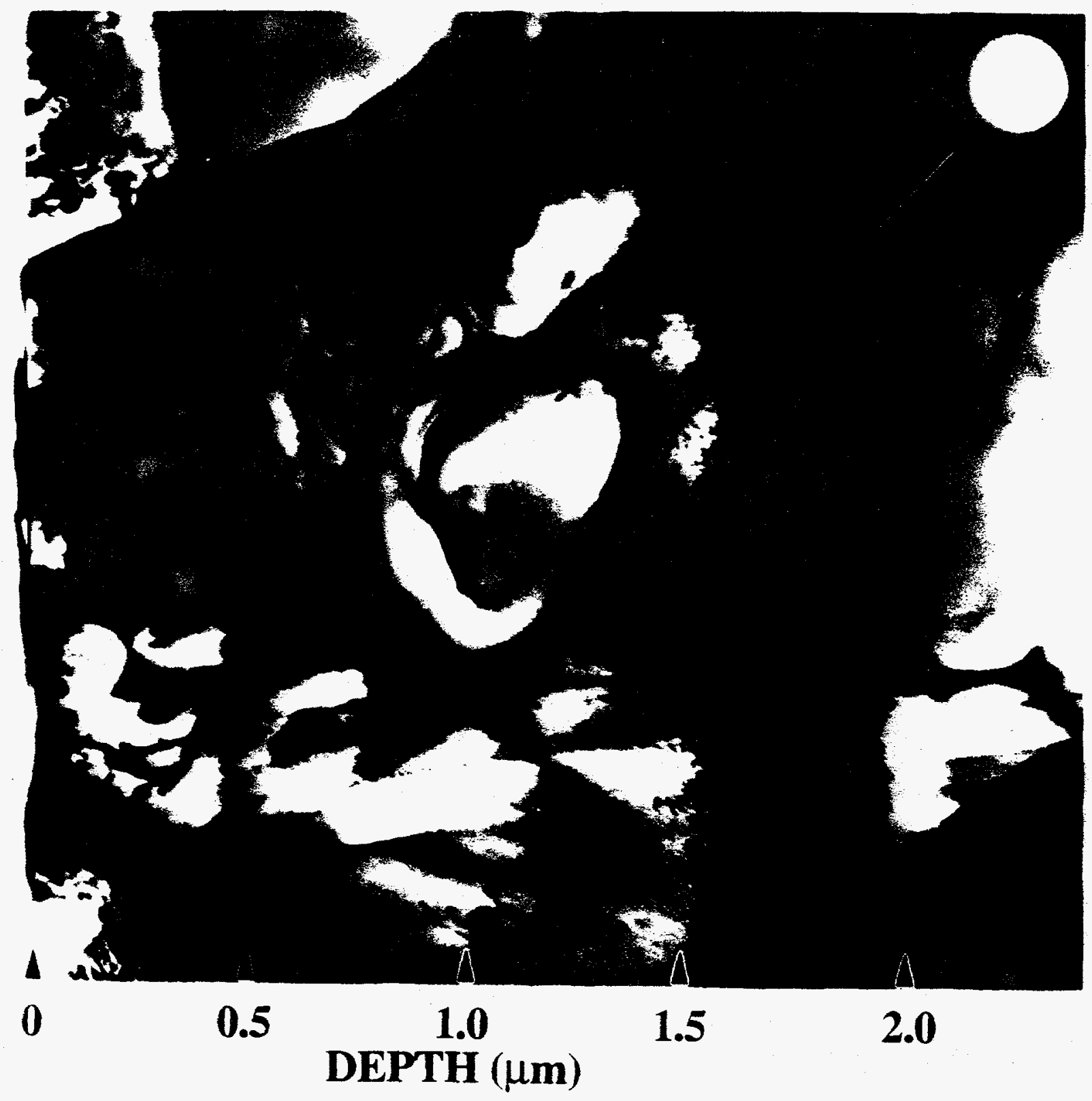


ORNL-PHOTO 6765-95

VO AMORPHIZATION IN Si3N4 IRRADIATED TO 10 DPA AT $300 \mathrm{~K}$ WITH DUAL BEAMS OF 3.6-MeV Fe+t AND 1-MeV $\mathrm{He}^{+}$IONS

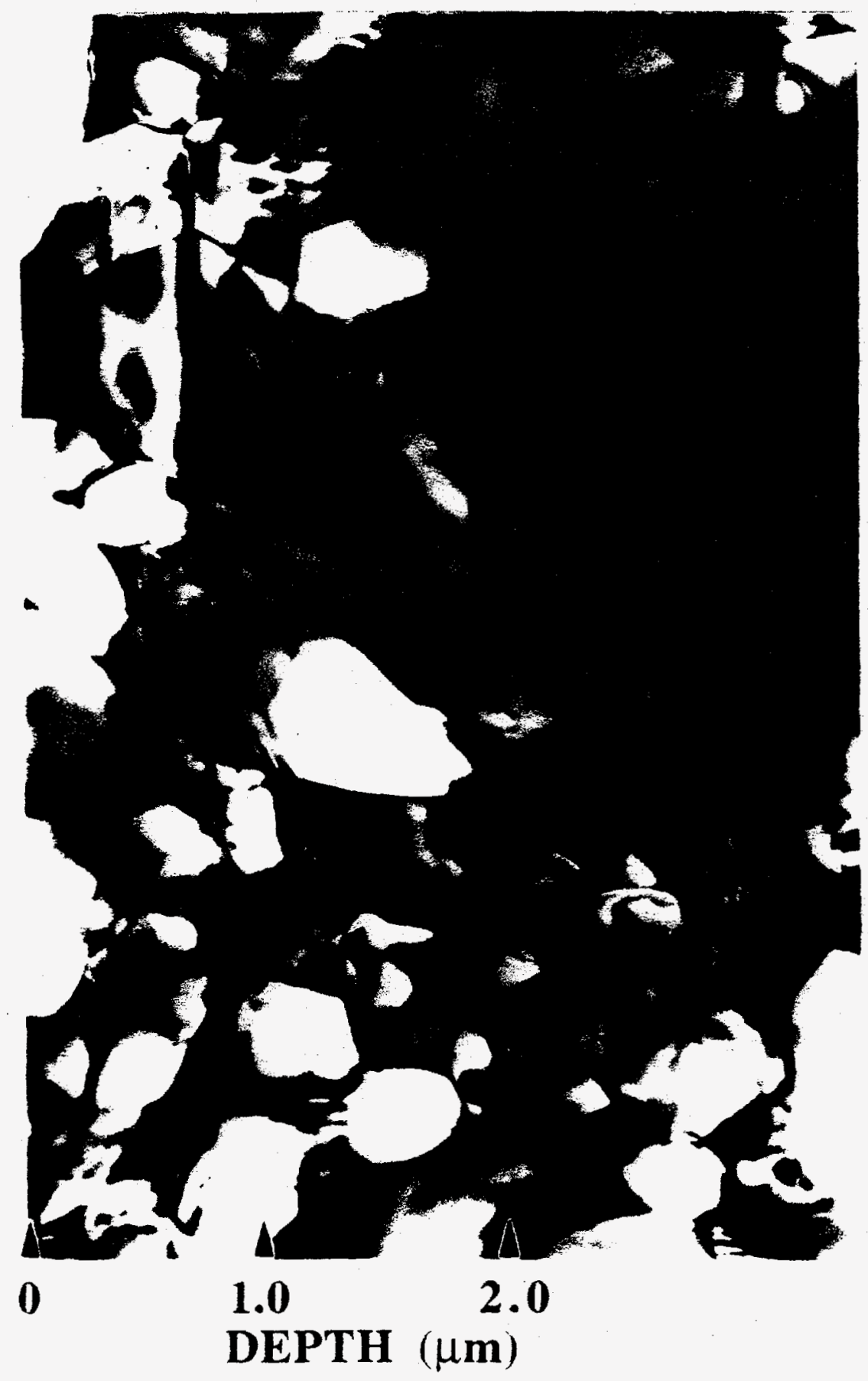




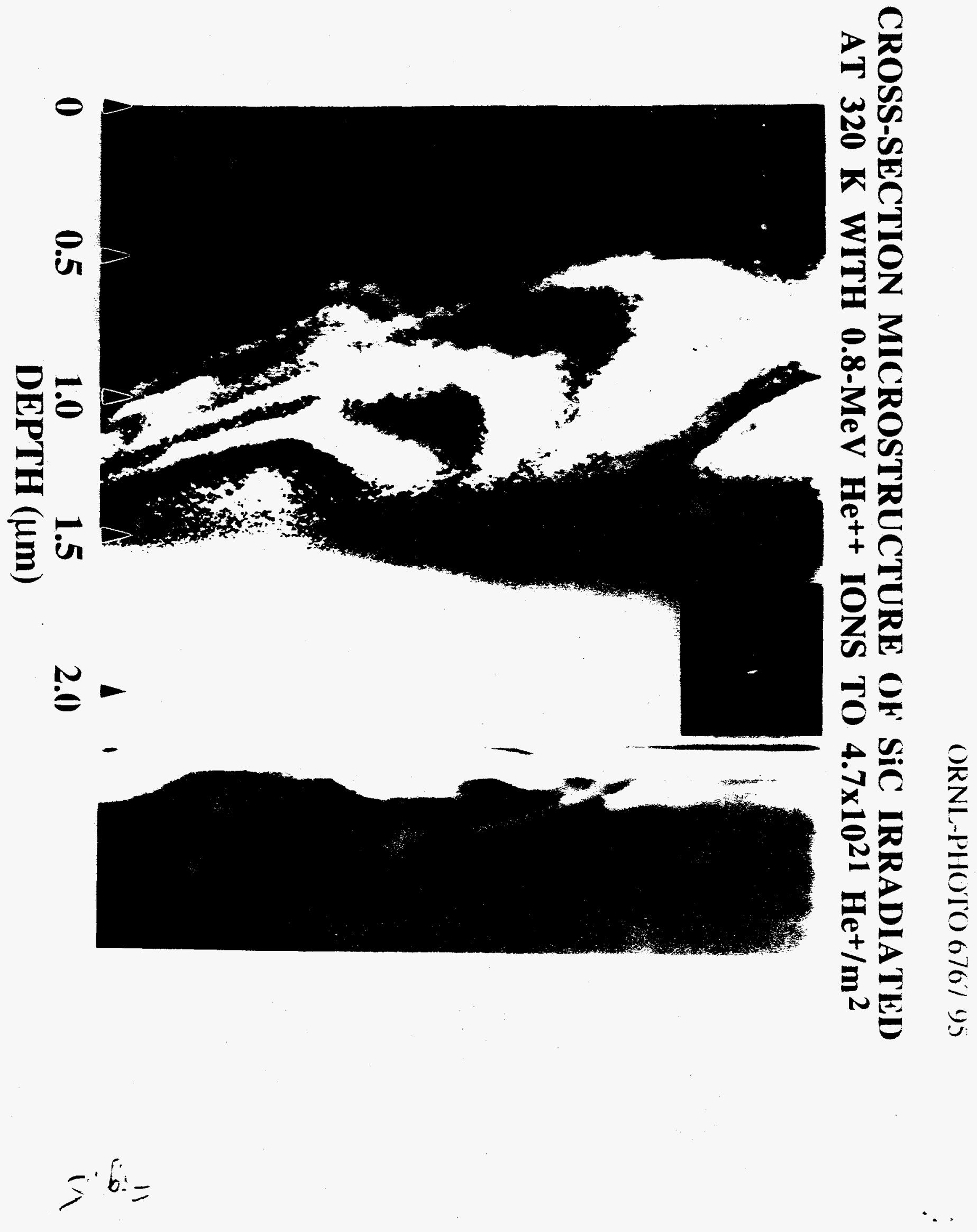


Fig.6

$n$
0
0
0
0
0
0
$\frac{1}{2}$
$\frac{1}{2}$
$\frac{1}{0}$

\begin{tabular}{|c|}
\hline 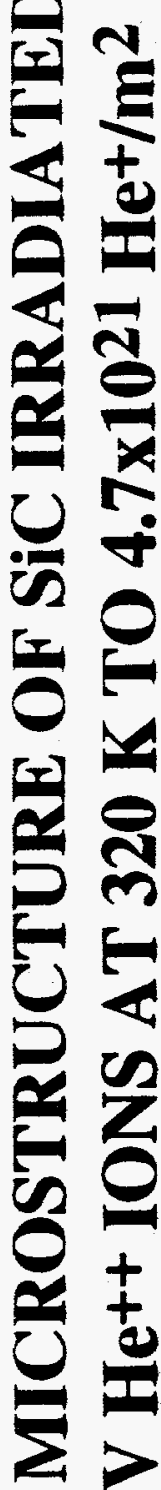 \\
\hline
\end{tabular}

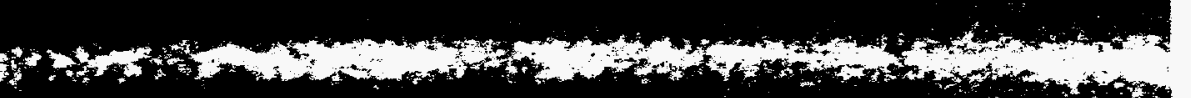

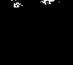

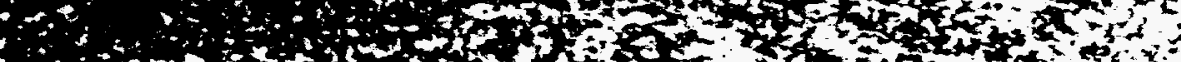

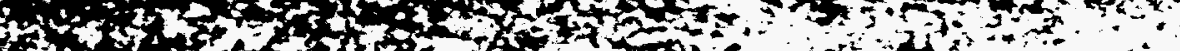

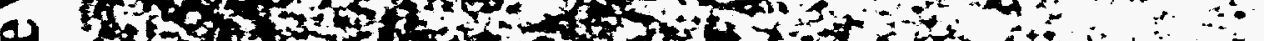

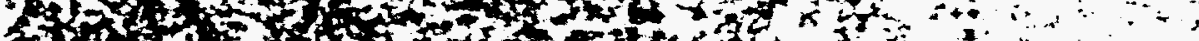

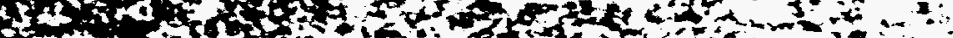

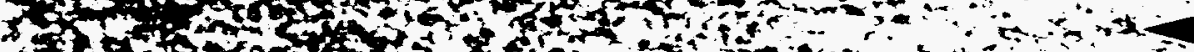

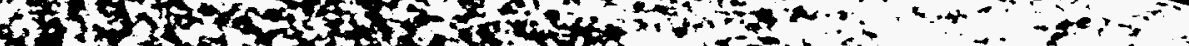

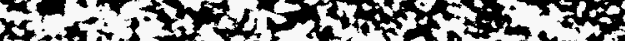

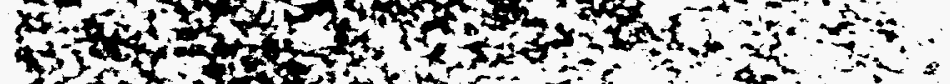

[x]

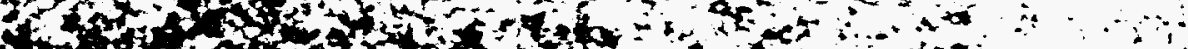

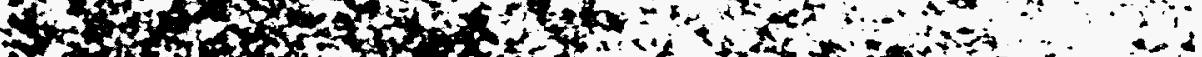

1

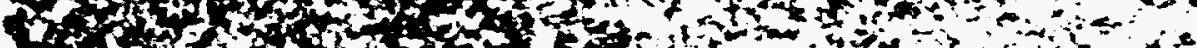

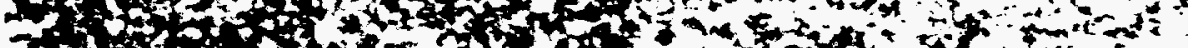

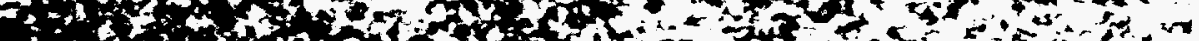

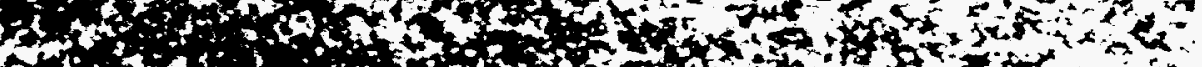

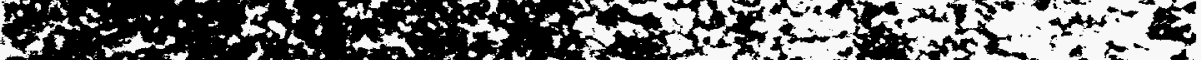

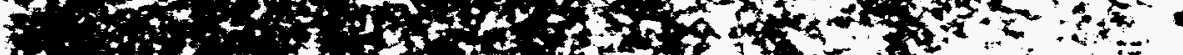

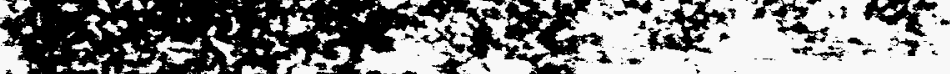

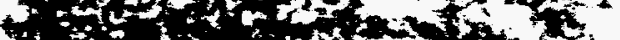

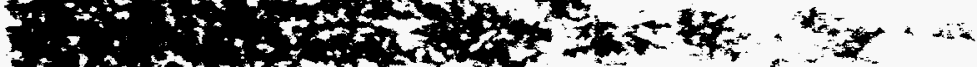


AMORPHIZATION AND SWELLING IN SIC IRRADIATED WITH $1.8 \mathrm{MeV} \mathrm{Cl}^{+}$and $1 \mathrm{MeV} \mathrm{He}+$ IONS AT $50^{\circ} \mathrm{C}$

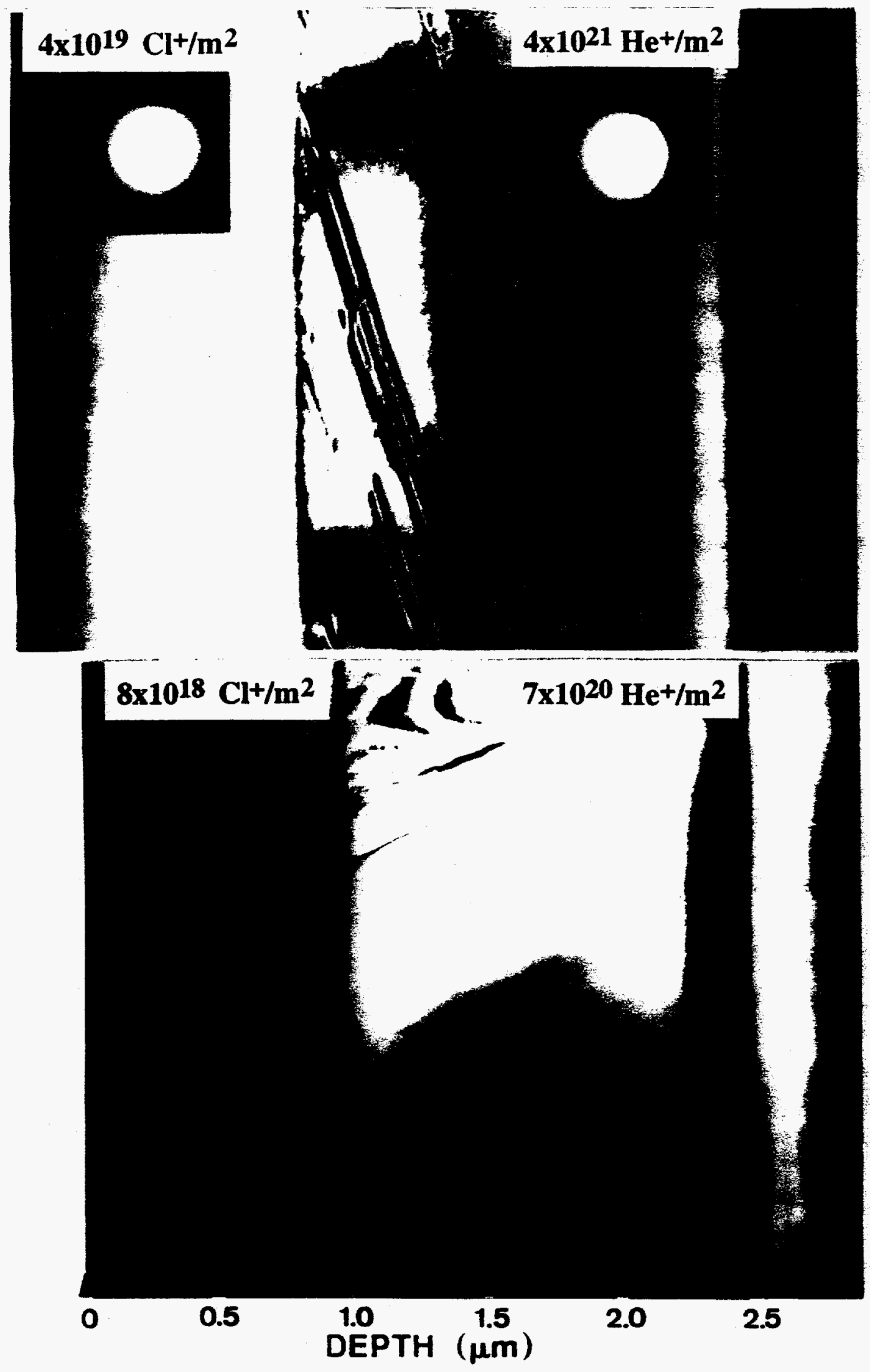




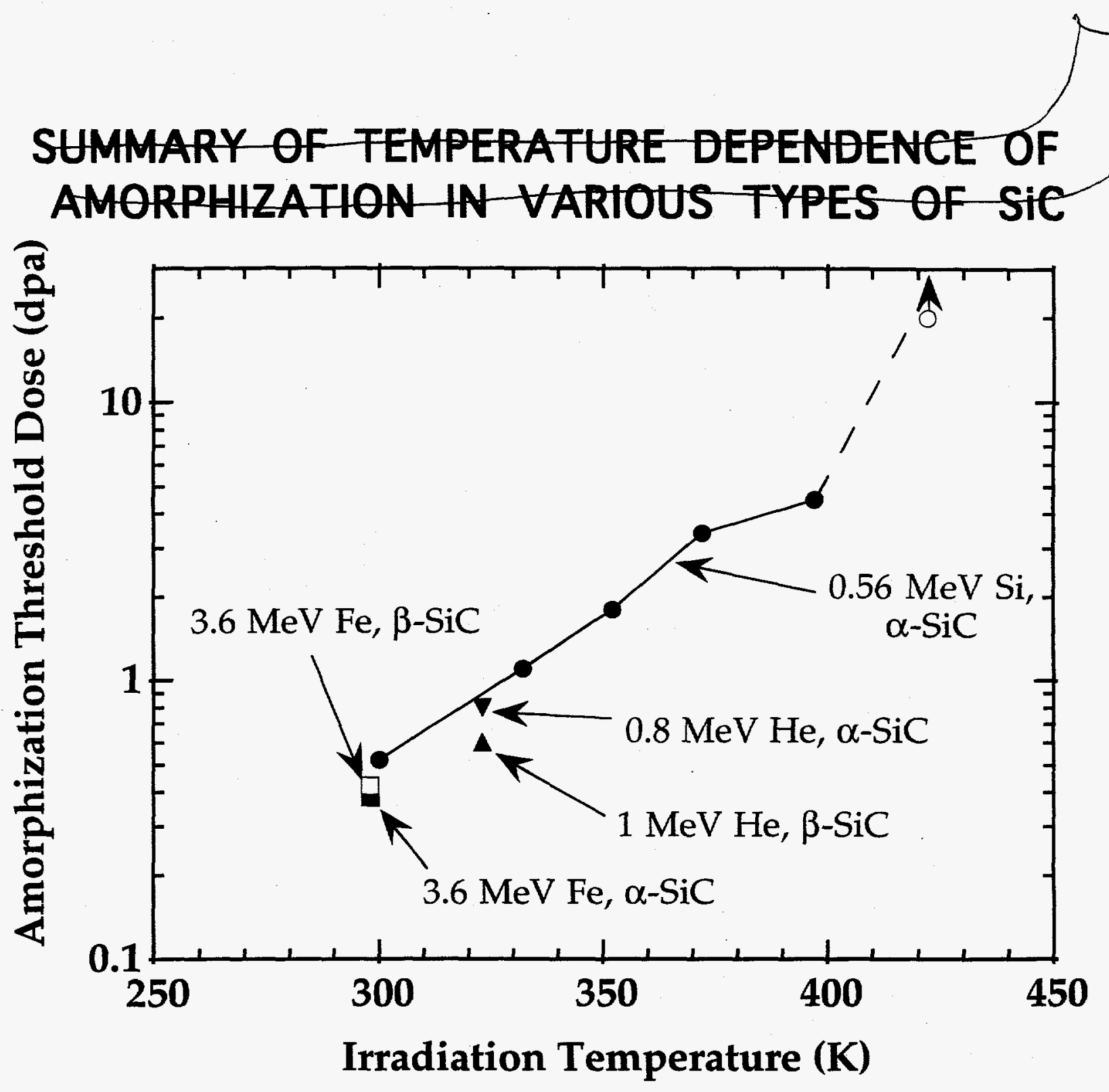


Effect of Irradiation Species and Temperature on the Amorphization Threshold Dose in SiC

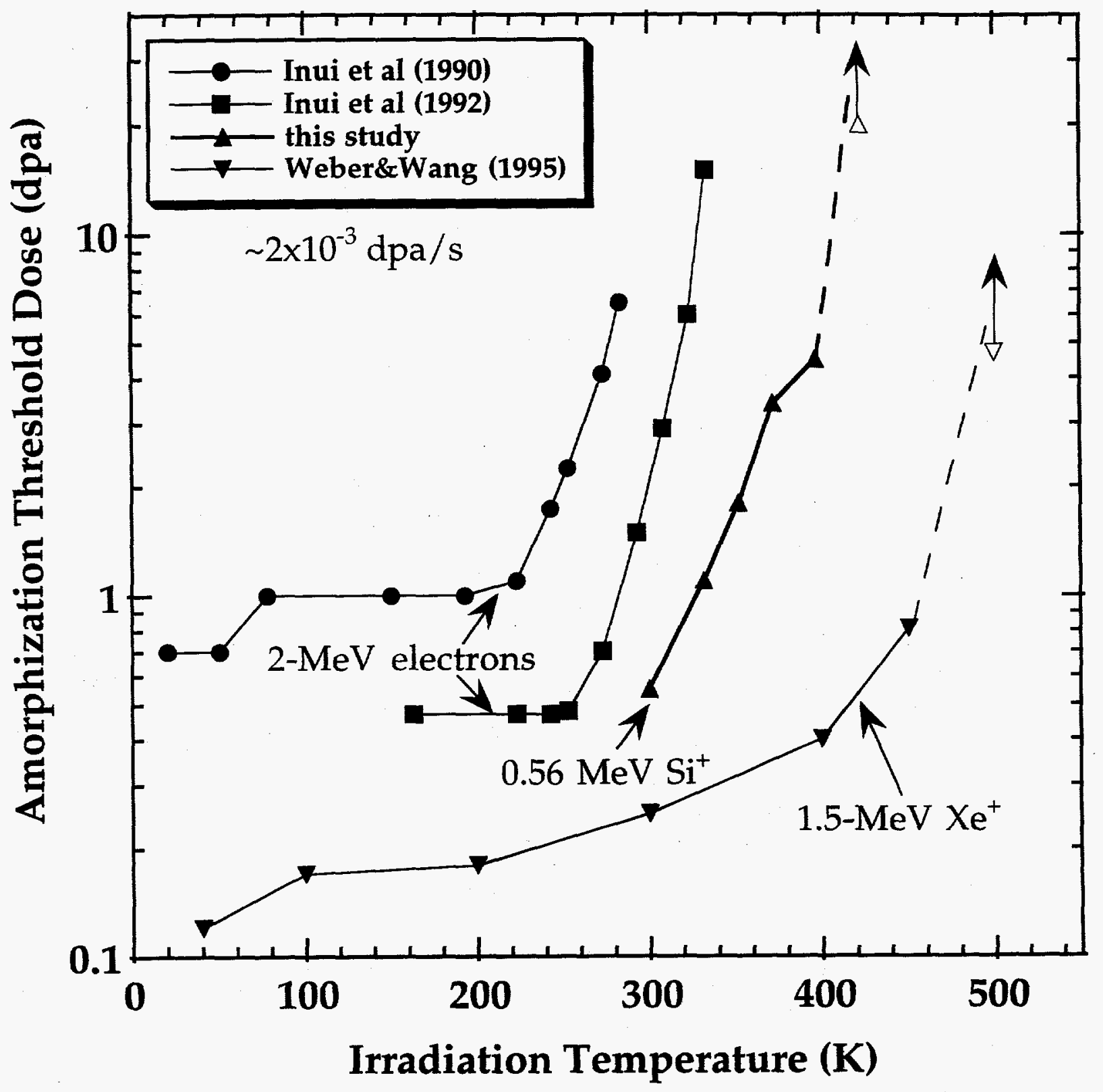

